\title{
Re-expansion pulmonary oedema after spontaneous pneumothorax treatment with chest tube placement
}

\author{
Denny Rodrigues (ㄱ, Margarida Valério, Teresa Costa
}

Pulmonology, Centro Hospitalar e Universitario de Coimbra EPE, Coimbra, Portugal

Correspondence to Dr Denny Rodrigues; dennymarques@gmail.com

Accepted 13 March 2021

Check for updates

C) BMJ Publishing Group Limited 2021. No commercial re-use. See rights and permissions. Published by BMJ.

\begin{tabular}{|l|}
\hline To cite: Rodrigues D, \\
Valério M, Costa T. BMJ Case \\
Rep 2021;14:e241734. \\
doi:10.1136/bcr-2021- \\
241734 \\
\hline
\end{tabular}

\section{DESCRIPTION}

Re-expansion Pulmonary oedema (RPE) is a rare but potentially fatal complication, which can arise after a rapid decompressive treatment of pulmonary collapse secondary to pleural effusion, pneumothorax or atelectasis. The pathophysiological mechanism is still poorly understood, admitting a multifactorial aetiology underlying the process of increasing the permeability of the pulmonary microvascular structure secondary to the abrupt re-expansion process. ${ }^{12}$

A 21-year-old male patient, active smoker (three pack-years), without drug abuse, recent trauma or pathological history. He was admitted to the emergency department after 6 days of sudden onset of dyspnoea, left pleuritic chest pain, palpitations and dry cough, with progressive worsening.

The patient had no evident morphological abnormalities, blood pressure was $112 / 68 \mathrm{~mm} \mathrm{Hg}$, heart rate $100 \mathrm{bpm}$, respiratory rate $22 \mathrm{bpm}$, peripheral oxygen saturation of $99 \%$ (room air) and was apyretic. He presented a hyper-resonant left haemithorax with decreased lung sounds on auscultation. Chest X-ray confirmed left tension pneumothorax (figure 1). Blood samples showed normal haemogram, coagulation and inflammatory parameters. The patient was then treated with oxygen therapy and placement of a chest tube on the fifth left intercostal space, with subaquatic seal (without suction), leading to improved symptoms.

One hour after the procedure he developed tachycardia, productive cough, dyspnoea and respiratory distress, unresponsive to oxygen therapy. A repeat chest X-ray confirmed the correctly positioned chest tube, complete left lung expansion, but showed alveolar opacities (figure 2). RPE was assumed and treatment with diuretics, corticosteroids and continuous positive airway pressure was initiated. As a result, the symptoms improved, and clinical stability was achieved.

The patient was transferred to intermediate care unit and positive pressure was stopped. One hour after, he underwent in to acute respiratory failure, requiring orotracheal intubation, invasive mechanical ventilation and admission into intensive care unit. He stayed on mechanical invasive ventilation for 6 days. At the 7 th day of intensive care unit stay, there was a complete resolution of RPE, but a persistent air leak was noted, so the patient was submitted to surgical pleurodesis (pleural abrasion) via video-assisted-thoracoscopy. He was discharged 10 days later, asymptomatic and with a normal chest X-ray.

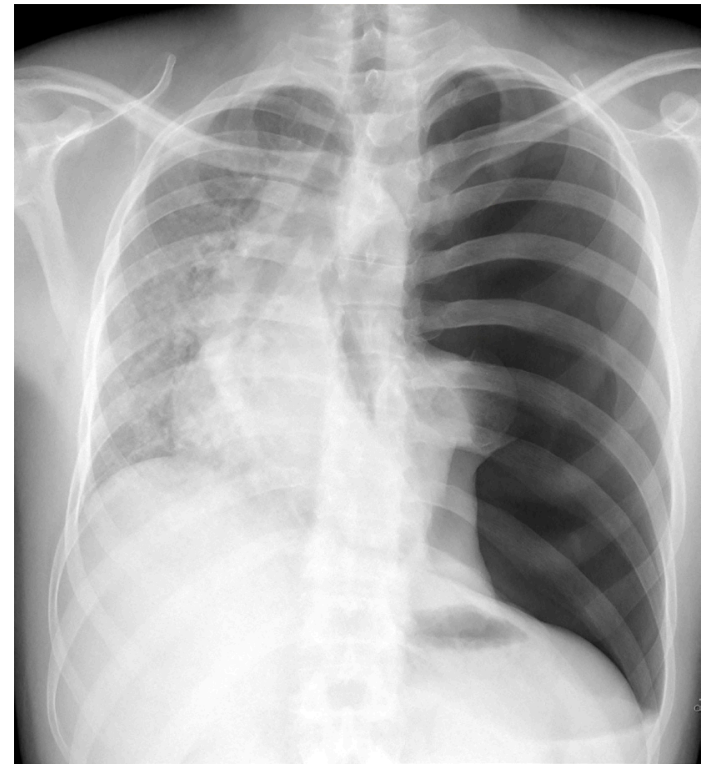

Figure 1 Chest X-ray showing complete left lung collapse, tracheal and mediastinal deviation to the right side.

The diagnosis of RPE is made by a combination of clinic and imaging findings. Most common symptoms include productive cough, tachycardia, hypotension, cyanosis, fever and chest pain. The severity of the symptoms is variable, from mild (documented only by imaging), to acute respiratory

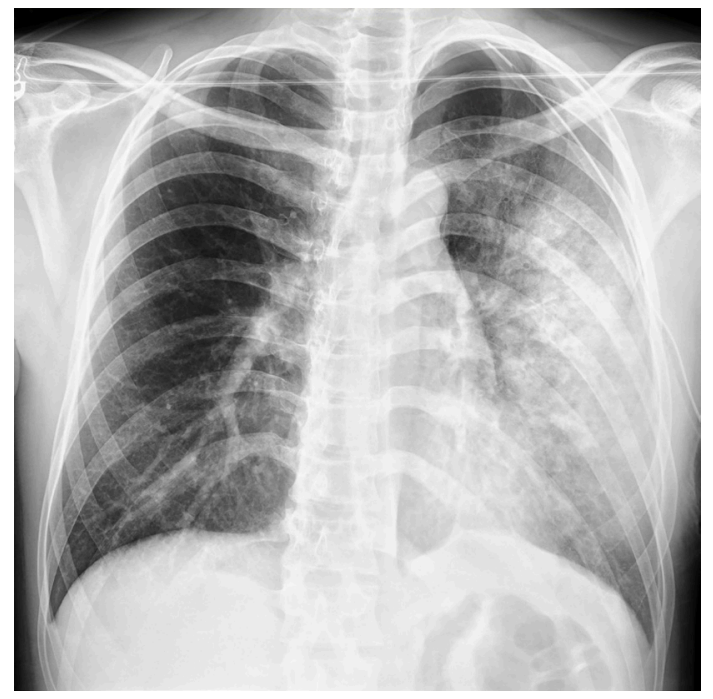

Figure 2 Chest X-ray showing alveolar opacities on the left lung, chest drainage tube with extremity positioned on the left lung apex. 


\section{Learning points}

Re-expansion pulmonary oedema can arise after a rapid decompressive treatment of the pneumothorax.

- The risk of occurrence increases with the pneumothorax duration and its size (increased risk for larger pneumothorax).

- Treatment is supportive care, but steroids, haemodynamic and ventilatory support may be needed.

distress syndrome. The most common finding in chest X-rays is an alveolar filling pattern, usually ipsilateral but it can reach any anatomical portion of the lung parenchyma. These findings usually arise between 2 and 4 hours after the thoracic cavity drainage, which can worsen in the first 48 hours and persist for four to 5 days, after which the oedema is expected to resolve, typically without sequelae. ${ }^{3-5}$

Stablished RPE risk factors include longer pneumothorax evolution, usually greater than 3 days and pneumothorax size, being the risk directly proportional to its size. It is usually a selflimiting complication that only requires supportive treatment, with oxygen therapy, diuretics and positive pressure therapy. In greater severity situations, systemic corticosteroid therapy is advised and invasive mechanical ventilation may be necessary. ${ }^{356}$

Contributors Substantial contributions to the conception or design of the work, or the acquisition, analysis or interpretation of data: DR, MV and TC. Drafting the work or revising it critically for important intellectual content: DR, MV and TC. Final approval of the version published: DR, MV and TC. Agreement to be accountable for all aspects of the work in ensuring that questions related to the accuracy or integrity of any part of the work are appropriately investigated and resolved: DR, MV and TC.

Funding This study was funded by Centro Hospitalar e Universitário de Coimbra (945074).

Competing interests None declared.

Patient consent for publication Obtained.

Provenance and peer review Not commissioned; externally peer reviewed.

ORCID iD

Denny Rodrigues http://orcid.org/0000-0003-0722-4843

\section{REFERENCES}

1 Kim YK, Kim H, Lee CC, et al. New classification and clinical characteristics of Reexpansion pulmonary edema after treatment of spontaneous pneumothorax. Am $\mathrm{J}$ Emerg Med 2009;27:961-7.

2 Mahfood S, Hix WR, Aaron BL, et al. Reexpansion pulmonary edema. Ann Thorac Surg 1988:45:340-5.

3 Matsuura $\mathrm{Y}$, Nomimura T, Murakami H, et al. Clinical analysis of Reexpansion pulmonary edema. Chest 1991;100:1562-6.

4 Gleeson T, Thiessen R, Müller N. Reexpansion pulmonary edema. J Thorac Imaging 2011;26:36-41.

5 Verhagen M, van Buijtenen JM, Geeraedts LMG. Reexpansion pulmonary edema after chest drainage for pneumothorax: a case report and literature overview. Respir Med Case Rep 2015;14:10-12.

6 Morioka H, Takada K, Matsumoto S, et al. Re-expansion pulmonary edema: evaluation of risk factors in 173 episodes of spontaneous pneumothorax. Respir Investig 2013;51:35-9.

Copyright 2021 BMJ Publishing Group. All rights reserved. For permission to reuse any of this content visit

https://www.bmj.com/company/products-services/rights-and-licensing/permissions/

BMJ Case Report Fellows may re-use this article for personal use and teaching without any further permission.

Become a Fellow of BMJ Case Reports today and you can:

- Submit as many cases as you like

- Enjoy fast sympathetic peer review and rapid publication of accepted articles

- Access all the published articles

Re-use any of the published material for personal use and teaching without further permission

Customer Service

If you have any further queries about your subscription, please contact our customer services team on +44 (0) 2071111105 or via email at support@bmj.com.

Visit casereports.bmj.com for more articles like this and to become a Fellow 